\title{
Abundance and size of birds determine the position of the species in plant-frugivore interaction networks in fragmented forests
}

\author{
S. Montoya-Arango ${ }^{1,3}$, J. F. Acevedo-Quintero ${ }^{2}$ and J. L. Parra ${ }^{1}$ \\ ${ }^{1}$ Grupo de Ecología y Evolución de Vertebrados, Instituto de Biología, Facultad de Ciencias Exactas y Naturales, \\ Universidad de Antioquia, Medellín, Colombia, C.P. 050010 \\ 2 Departamento de Ciencias Forestales, Facultad de Ciencias Agrarias, Universidad Nacional de Colombia, Medellín, \\ Antioquia, Colombia, C.P. 050034 \\ ${ }^{3}$ Corresponding author.sergioama123@gmail.com
}

Keywords: Fragmentation, Frugivory, Tropical forests.

\begin{abstract}
The relationships between frugivorous animals and plants are of vital importance particularly in tropical forests. The way species interact and how they are organized within interaction networks could be determined by their ecological and morphological characteristics. This study evaluates the hypothesis that the topological position of species within an interaction network is determined by their degree of frugivory, body size, and abundance. Thus, we constructed the frugivory network between birds and plants in a rainforest fragment in northwestern Colombia. The position of the species within the network was calculated based on three centrality measures (degree, betweenness, and closeness), and its association with relative abundance, degree of frugivory, and body size of each bird species was evaluated by means of a generalized linear model. We found that the species that were most abundant and had the smallest body size had central positions in the interaction network. This pattern is contrary to what has been observed in pristine forests, where species with large body size are more important for network stability. Our results suggest that forest fragmentation modifies the roles of species within the network structure, in part, due to changes in the makeup of the original frugivore community. The information presented may be useful to evaluate the effects of the loss of species as a result of anthropic actions, with the aim of generating ecosystem restoration strategies.
\end{abstract}

Nomenclature: We followed plant species nomenclature APG IV (APG IV 2016) and the bird species nomenclature by South American Classification Committee (Remsen et al. 2018).

Abbreviations: BC-Betweenness, CC-Closeness, ND-Degree, PCA-Principal Components Analysis.

\section{Introduction}

Trophic interactions between plants and frugivores are of vital importance in the structure of ecosystems, especially in tropical forests where 70 to $90 \%$ of woody species are animal-dispersed (Howe and Smallwood 1982, Jordano 2000). There is evidence that suggests that one of the main consequences associated to processes of forest fragmentation is the loss of large frugivores, which could lead to changes in the dynamics of the plant community (Renjifo 1999, Markl et al. 2012), and eventually has repercussions on how ecosystems function. While over the last decade there has been an increase in the amount of studies on frugivory networks in tropical forests (Escribano-Avila et al. 2018), the specifics of such networks in disturbed lowland forests are still being discussed. In northwestern Colombia, a large region of lowland rainforests has been seriously affected due to extensive cattle farming and banana plantations, which have replaced a large part of the original land cover, leaving few remnants in a large matrix of plantations. In this study, we describe the frugivory network in one of these fragments and evaluate several hypotheses concerning the ecological and morphological characteristics of the birds with respect to network to- pology. Our aim is that the results of this study may serve as the foundation for the development of strategies of ecosystem restoration

Interaction networks present a series of topological patterns which are related to the stability and robustness of the system when facing species loss (Bascompte and Jordano 2007, Tylianakis et al. 2010). Likewise, the amount, distribution, and identity of the interactions of each species make the structural importance of the species vary (Martín González et al. 2010, Saavedra et al. 2011, Vidal et al. 2014, Palacio et al. 2016). Also, the differences in interaction patterns amongst species may be determined by their ecological and morphological characteristics (Olesen et al. 2011, Dehling et al. 2014, 2016), which are related to the susceptibility to anthropic pressures (Ceballos and Ehrlich 2002, Dirzo et al. 2014). Considering the importance of frugivory interactions, it is necessary to identify which species are relevant in the structure of the interaction network and evaluate whether such species exhibit particular ecological and morphological traits. This information may be associated with the conditions of conservation of a particular site, generating new conservation tools in order to identify the impacts on biodiversity 
and suggest the implementation of measures in the field of ecosystem restoration.

Birds are considered the main group of seed dispersal animals in the tropics (Howe and Smallwood 1982), and the study of this relationship from a network perspective has increased over the past years (Bascompte and Jordano 2007, Escribano-avila et al. 2018). Some authors have suggested that characteristics such as specialized diets (degree of frugivory) determine the importance of species in interaction networks and, thus, consider that the most specialized birds are the most important to maintain network structure (Mello et al. 2014, Sarmento et al. 2014). Likewise, body size may be of great relevance due to the fact that species with greater body size contribute substantially to fruit removal (Muñoz et al. 2016, Donoso et al. 2017a); and thus the most important (Donatti et al. 2011, Palacio et al. 2016). Lastly, interaction patterns are also determined, to a certain degree, by the abundance of the species, since species that are more abundant tend to interact more amongst themselves than with rare species (Vázquez et al. 2007, Jordano et al. 2009, Donoso et al. 2017a). However, it remains unclear which species characteristics determine importance within dispersal networks (Escribano-Avila et al. 2018).

On the other hand, anthropic disturbances exert pressure on the environmental and ecological characteristics of the ecosystems. Among human activities, habitat destruction has been the main cause of biodiversity loss (Pimm et al. 2006), including birds (Buckton 2001). Thus, in disturbed ecosystems, habitat destruction and fragmentation may alter how frequently certain morphological traits appear or modify the ecological attributes of the communities such as species abundance (Renjifo 1999, Peres and Palacios 2007, Markl et al. 2012). For example, in the tropics, large frugivorous birds are the most vulnerable to extinction due to forest fragmentation and other human related activities like hunting (Kattan et al. 1994, Renjifo 1999, Pimm et al. 2006). The link between body size, fragmentation, and extinction risk is complex and related to several demographic parameters such as abundance, population fluctuations, and population growth rates (Henle et al. 2004), that respond directly to changes in available habitat, but also indirectly through changes in the trophic interactions among species (Feeley and Terborgh 2008). Species at the top end of food chains are often large, have lower population densities, and are regarded as more extinction prone than those at lower levels (Gard 1984). Therefore, if anthropic pressures negatively select certain ecological and morphological traits (e.g., large species), this alteration will inevitably affect the network interaction patterns, which will reflect upon the distribution of the importance of species in the network structure.

In this study, we described the frugivory interaction network between plants and birds in a humid tropical forest in the Urabá plains of Antioquia department in Colombia. We evaluated the relationship between the ecological and morphological characteristics of birds and the importance of the species within the network structure. Therefore, we used centrality as a measure that quantifies the importance of a species by the position it holds within the network structure (Barthélemy 2004, Jordán et al. 2006), and the interaction with particular traits of the bird species. Our hypothesis was based on the concept that the structural importance of species is determined by the degree of frugivory, body size, and abundance. We expected the largest obligate, most abundant frugivores to present the highest centrality values confirming their role as the most important species in the network structure.

\section{Materials and methods}

\section{Study area}

Samples were taken from a fragment of a tropical rainforest in the biogeographical region of Chocó, located at the Sede de Estudios Ecológicos y Agroambientales Tulenapa (Headquarters of Ecological and Agro-environmental Studies), in northwestern Antioquia, Colombia ( $07^{\circ}$ $46.391^{\prime}$, W $\left.76^{\circ} 40.306^{\prime}\right)$. Tulenapa is approximately 60 meters above sea level and has 193 ha, of which 146 ha are made up of natural vegetation with some patches in varying states of conservation, within a matrix of banana plantations. Aerial crop dusting is frequently conducted with pesticides in the surrounding plantations, which could affect biodiversity in many ways as well as increase the vulnerability of the site. Tulenapa is the largest fragment of native forest on the Leon river plain that has been heavily transformed into banana and plantain crops (Etter et al. 2006, Sánchez-Cuervo and Aide 2013). Research and conservation projects have been recommended for this region (Colorado 2013), but there is still little known about this highly threatened zone.

Within this forest fragment, the samples were distributed in three permanent, 1-hectare plots that had been previously established by the herbarium at the Universidad de Antioquia, and along the path that surrounds Tulenapa. The plots corresponded to different successional stages, and were referred to as initial succession, intermediate succession, and advanced succession. Within the plots, all trees with $>31.4 \mathrm{~cm}$ circumference at chest height and bushes with $>1 \mathrm{~cm}$ circumference at chest height in a $1600 \mathrm{~m}^{2}$ subplot were marked and labeled, which made it easier to identify the species that had fruit. The early succession plot contains 937 individuals corresponding to 83 species, the intermediate succession plot contains 674 individuals corresponding to 126 species and the advanced succession plot has 1341 individuals from 181 species accumulating a total of 256 species in the three plots, of which 148 species were identified as potentially consumed by birds.

\section{Data collection}

Interaction record. Eight field trips were conducted between May 2016 and April 2017, at intervals of at least one month and with a duration of four to seven days each, including the dry (three trips in September and between February and early April) and rainy seasons (five trips between May and July and between October and November). In order to increase the probability of detecting infrequent interactions, a com- 
bination of methods between trail walks and focal observations were used (Jordano 2016) within the plots and along the path. Every day, between two and four observers registered all frugivory events between birds and plants in two shifts $(6: 00-11: 00$ a.m. and 3:30 - 6:00 p.m.). A frugivory event was defined as a visit where a bird ate at least one fruit from the observed plant. Each time such an event was recorded, a 4-minute focal observation was conducted on the tree/bush that had been visited recording the date, time, plot, plant species visited, bird species, and the number of birds that ate fruit from the plant. If a new interaction was recorded during the last minute of observation, focal observation was extended one minute.

Ecological and morphological characteristics. In order to identify which characteristics determine the importance of a bird species within an interaction network, certain ecological and morphological traits that characterize the species which make up the network were selected. Degree of frugivory was evaluated by categorizing according to degree of specialization in the diet of the species; those for which over $50 \%$ of their diet was based on fruit were considered "obligate", those for which $20-50 \%$ of their diet was based on fruit were known as "partial", and those for which under $20 \%$ of their diet was based on fruit were called "opportunistic". Likewise, data was collected for each bird species concerning body mass as a proxy for size. Data were obtained using EltonTraits 1.0 database both for degree of frugivory and body mass (Wilman et al. 2014).

In order to estimate the abundance of birds, we used the record from each of the counting sites. During each sampling shift, there was a counting site in the center of each plot, or at the edge of the forest, which had a radius of 50 meters. Counting lasted 15 minutes and consisted in recording bird species and number of each species sighted and/or heard (Bibby et al. 1998). Frequency was then calculated as the proportion of counting sites in which a specific species was recorded with respect to total counting sites. Overall, between 15 and 18 counting sites were conducted for each sampling unit.

\section{Data analysis}

A quantitative interaction matrix was made using the data collected (Supplement, Table A2), where each row included a bird species $(\boldsymbol{i})$, each column included a plant species $(\boldsymbol{j})$ and the $\boldsymbol{i}, \boldsymbol{j}$ cell was assigned the interaction strength value identified as the number of frugivory events registered during the entire sampling (Vázquez et al. 2007). In order to evaluate sample representativeness, an interaction accumulation curve was constructed with the number of unique interactions observed as a function of sampling effort, measured as the number of interactions registered (Chacoff et al. 2012, Jordano 2016). In this procedure, the estimated number of expected interactions was calculated using the Chaol estimator and was compared to the number of observed interactions (Chao et al. 2009). Calculations were performed using 1000 iterations and EstimateS 9.1.0 software (Colwell 2013).
We estimated the percent number of observed interactions in our samples following Chacoff et al. (2012):

$\% \mathrm{SO}=100(\mathrm{SO} / \mathrm{SE})$,

where SO is the observed richness of species or interactions observed and $\mathrm{SE}$ is the expected richness or the total number of expected interactions estimated with Chao 1 .

In order to quantify the relative importance of the species within the network structure, three centrality measures were calculated based on the interaction matrix: $i$ ) Degree (ND): this quantifies the amount of interactions for each species (e.g., species with high ND values make up a large part of the network interactions; ii) Betweenness (BC): it is defined as the proportion of the shortest paths between all pairs of network species that pass through a determined species (Newman 2003). High BC values are interpreted as species that unite two or more different guilds within a community (Martín González et al. 2010, Mello et al. 2014); and iii) Closeness (CC): it measures the proximity of one species to all other network species (Estrada 2007, Sazima et al. 2010). In ecological terms, a bird species presents high $\mathrm{CC}$ values when it eats plant species which are also eaten by many other birds, while it has low values when its diet is more unique (Martín González et al. 2010, Mello et al. 2014). To calculate $\mathrm{BC}$ and $\mathrm{CC}$, a one-mode projection of the matrices was used, where two frugivore species are connected when they feed on at least one plant species in common (Mello et al. 2014), this projection includes edge weights (i.e., frequency of an interaction). All calculations were conducted using R-package bipartite, 3.4.0 (Dormann et al. 2017).

Principal components analysis (PCA) was used in order to create a single general centrality measure containing the information from all three measures. The first component (PC1) was used as a descriptor of the structural role of each species within the network (Estrada 2007, Sazima et al. 2010, Vidal et al. 2014). Prior to the PCA calculation, data were standardized in z-scores, with a mean of 0 and standard deviation of 1 (Estrada 2007).

Lastly, a generalized linear model was constructed in order to determine how the ecological and morphological traits of the species determine their structural role (Fox 2015). For this model, the general centrality measure was used as a dependent variable and degree of frugivory, body size, and abundance as explanatory variables. Calculations were performed using R 3.4.2 software (R Core Team 2017) lme4 package (Bates et al. 2015).

\section{Results}

During field sampling, 47 species were found in fruiting inside the three plots and ten additional species were found outside them. Besides, 523 frugivory events were recorded including 32 plant species and 45 bird species with a sampling effort of 551 hours per observer, which resulted in 132 different interactions, reaching representativeness of $79.3 \%$ of the interactions expected according to the Chao 1 estimator (mean: 166.52 interactions; confidence interval (95\%): 
148.95 - 202.32 interactions). Based on centrality measures, principal component analysis shows that the first principal component explains $67.4 \%$ of variation of data. To interpret this measure, negative values indicate peripheral species, whereas positive values indicate species that are more central and probably have an influence on network dynamics (Sazima et al. 2010, Fig. 1). Twenty one species were identified as central or important, including Psarocolius decumanus, *Catharus ustulatus, Thraupis episcopus, and Piranga rubra as the most relevant species (Supplement, Table A1).
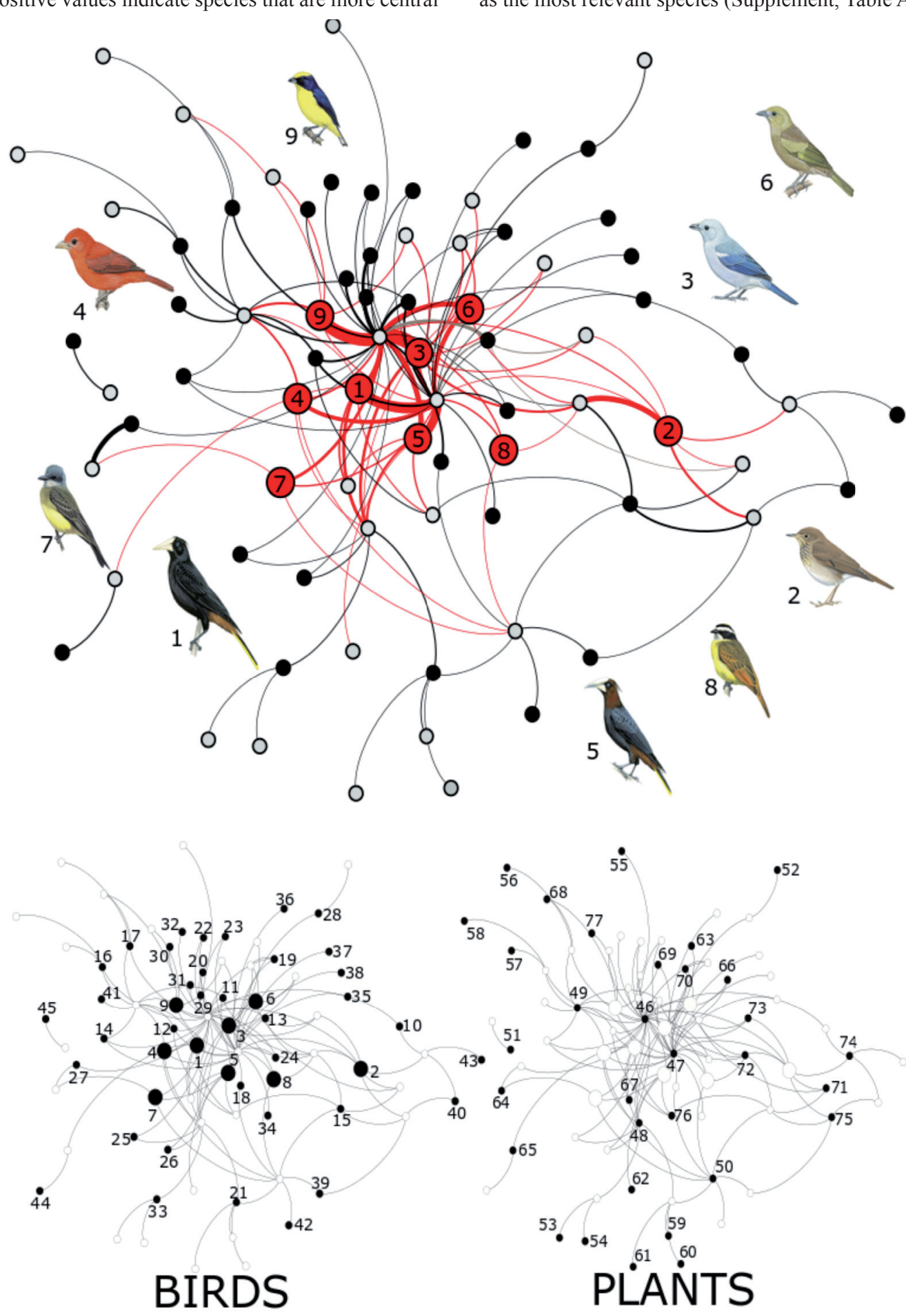

Figure 1. Plant-frugivore interaction network observed in the forest fragment. Gray nodes represent the plants, black nodes the birds, and nodes with inner numbers emphasize the birds with the highest centrality values. The thickness of the lines is proportional to the strength of the interaction between two species. The influence of birds with high centrality values (nodes with inner number), extends to a large portion of the central core of the network and also reaches the peripheral areas. Two lower panels can be used to identify any node (bird or plant) with Table A3 in the supplementary material. 
Table 1. Generalized linear model that evaluates the effect of ecological and morphological variables on the structural importance of bird species (centrality) in a plant-frugivore network in a tropical rainforest in northwestern Colombia. * significant at $\mathrm{p}<$ $0.05 ; * *$ significant at $\mathrm{p}<0.001$.

\begin{tabular}{lcccc}
\hline & Estimate & $\begin{array}{c}\text { Standard } \\
\text { error }\end{array}$ & $\mathrm{t}$-value & $\mathrm{P}$ \\
\hline $\begin{array}{l}\text { Obligate } \\
\text { frugivore }\end{array}$ & -0.14 & 0.22 & -0.63 & 0.53 \\
$\begin{array}{l}\text { Opportunistic } \\
\text { frugivore }\end{array}$ & 0.22 & 0.39 & 0.57 & 0.57 \\
$\begin{array}{l}\text { Partial frugivore } \\
\text { Abundance }\end{array}$ & 0.34 & 0.39 & 0.89 & 0.39 \\
Body size & 0.91 & 0.15 & 6.02 & $4.34 \mathrm{e}-07 * * *$ \\
\hline
\end{tabular}

Generalized linear models show that abundance and body size may partially explain the variation in relative importance of birds in the network structure (Table 1), where the most important birds were those which were most abundant and smallest in body size (Centrality $=8 \mathrm{e}-11+0.9247^{*}$ Abundance $-0.4457 *$ Body_Size; Figure 2).

\section{Discussion}

In this study, we described the structure of a frugivory interaction network in a fragment of a lowland tropical rain-

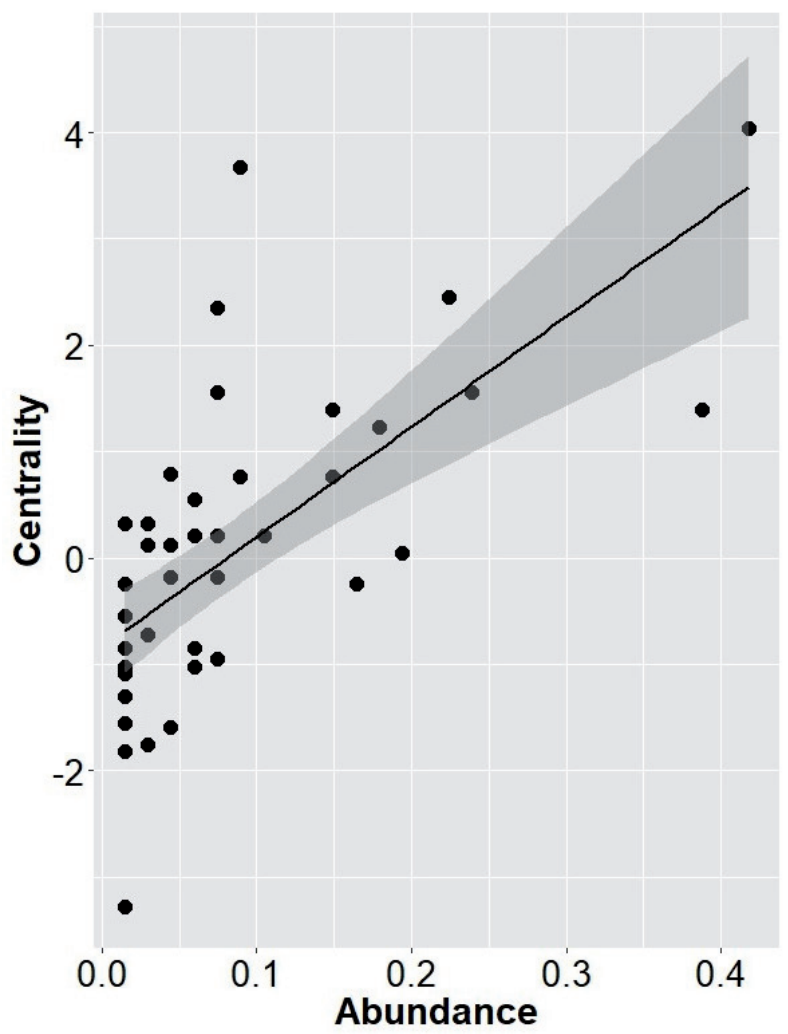

forest and identified important differences with respect to patterns reported in other studies. Unlike that which has been reported in pristine forests, where large species provide great stability to the network (Donatti et al. 2011, Muñoz et al. 2016, Donoso et al. 2017b), our results highlight the importance of species which are smaller but relatively abundant. The stated hypothesis that structural importance of species is determined partly by the degree of frugivory was not supported by our data. We suggest that this difference may be due to the high degree of intervention in this forest fragment, which, though it has partially maintained its vegetation structure, has lost a large amount of its original disperser community. Hereafter, we will discuss the relationships found amongst each of the variables, how this relates to the particular characteristics of the study area, and the implications concerning conservation.

With respect to degree of frugivory, our results are contrary to what has been reported in other studies (Mello et al. 2014, Sarmento et al. 2014, Sebastián-González 2017), since there was no relationship between this variable and the structural importance of the species. This tendency may be due to the particularly disturbed conditions of the study area (fragmentation, land-use change, crop dusting, isolation), where the composition of the community of obligate, frugivorous birds may be locally affected. For example, species like the Great Curassow (Crax rubra), and the trogons (Trogon massena, T. melanurus, and T. viridis) that were observed in nearby forests approximately 50 years ago (Escobar-Cardona

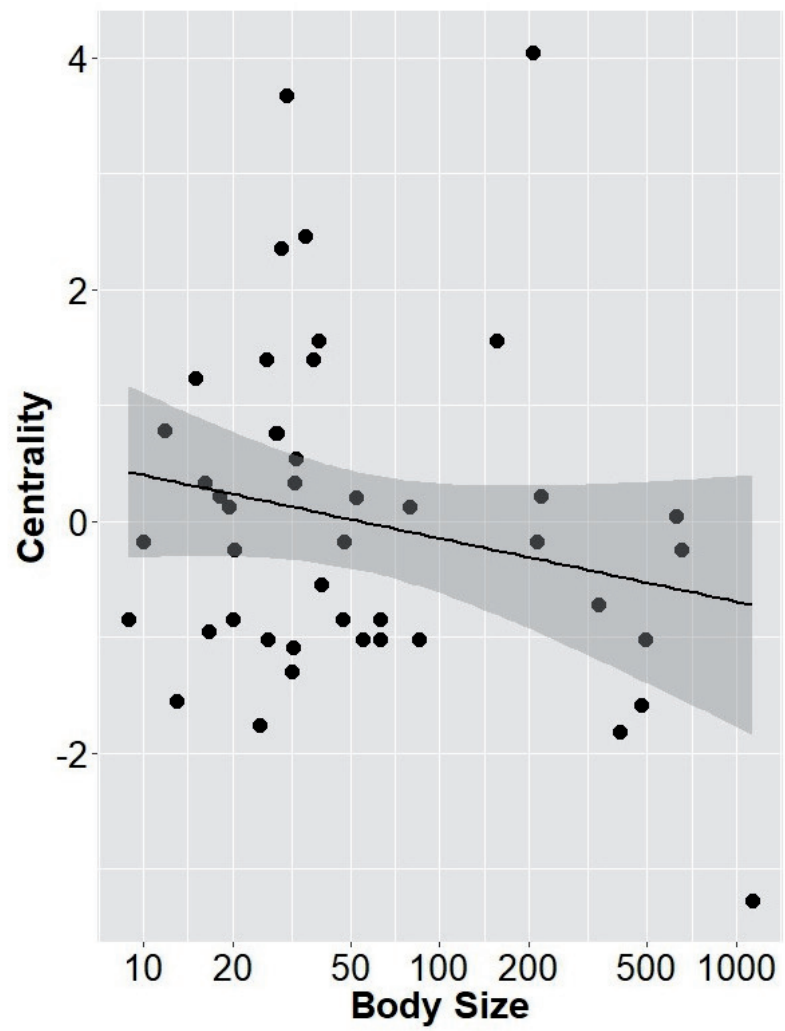

Figure 2. Linear regression models for abundance $\left(\mathrm{R}^{2}=0.44 ; \mathrm{p}<0.001\right)$ and body size $\left(\mathrm{R}^{2}=0.12 ; \mathrm{p}=0.017\right)$ variables with respect to the structural importance of bird species (centrality), in a plant-frugivore interaction network in a tropical rainforest in northwestern Colombia. Body size in grams, logarithmic axis. 
and Alvarez-Lopez 1966), have not been recently recorded in Tulenapa (Audubon and Cornell Lab of Ornithology 2018). This supports the idea that habitat loss and changes in vegetation composition in a particular area considerably affect species with a certain degree of specialization, where strict frugivores are particularly vulnerable to environmental fluctuations that affect food availability (Christiansen and Pitter 1997). For example, in seasons of low fruit production, there may be a serious decrease in population size that may even lead to local extinction (Christiansen and Pitter 1997). As a result, the distribution pattern of trophic guilds of the area may have shifted and could differ from its original composition, and is now dominated by generalist species with diets that are not strictly linked to fruit. For example, based on bird listings reported on the eBrid platform (Audubon and Cornell Lab of Ornithology 2018), obligate frugivores in Tulenapa make up $16 \%$ of species, whereas at the nearby "La Alborada" farm, which is in a better state of conservation, obligate frugivores reach $24 \%$. In this new scenario with few obligate, frugivorous species (or with reduced populations) their relevance within the network structure may be affected.

In a similar manner, habitat modifications and disturbances may explain the tendency of the relationship between body size of the birds and structural importance. Our results suggest that the smallest birds are the most relevant, an inverse relationship to the one that has been reported by other authors (Donatti et al. 2011, Palacio et al. 2016). Once again, it is not uncommon that fragments of small or isolated forests lack the resources necessary for the maintenance of large frugivores (Karr 1976, Willis 1979), where interactions involving large species disappear resulting in functional implications (Emer et al. 2018). In addition, other pressures such as selective tree cutting and hunting tend to affect the larger species first, and are thus quickly removed from disturbed forests (Redford 1992, Renjifo 1999, Markl et al. 2012). For example, it has been reported that populations of large frugivores such as the Black-necked Aracari (Pteroglossus aracari), the Spot-billed Toucanet (Selenidera maculirostris), and the Redbreasted Toucan (Ramphastos dicolorus), amongst others, have been considerably reduced in forests of nearly 200 hectares (Christiansen and Pitter 1997). Likewise, in our study area, large frugivores, such as the Crested Guan (Penelope purpurascens), the Purple-throated Fruitcrow (Querula purpurata), and the Great Curassow (Crax rubra), which have been recently recorded in nearby locations (Audubon and Cornell Lab of Ornithology 2018), may have become locally extinct. Therefore, the composition of the local avifauna is mainly made up of small, generalist species, which, due to their abundance, occupy central positions in the network that we believe were previously occupied by larger frugivores. However, many of these small, frugivorous species have also disappeared from these fragments and have been replaced by species that are more generalists in their feeding habits.

The consolidation of an abundant generalist guild is supported by our results with respect to abundance, where the most important bird species within the network are also the most abundant and are commonly labeled as generalists, such as the Crested Oropendola (Psarocolius decumanus), the Blue-gray Tanager (Thraupis episcopus), the Chestnutheaded Oropendola (Psarocolius wagleri), and the Palm Tanager (Thraupis palmarum). This pattern can be explained using the following reasoning: in tropical ecosystems, large species are generally more scarce than smaller species (Peres and Palacios 2007, Markl et al. 2012); this difference may also be more evident due to a decrease in the population of large species as a result of anthropic effects. Also, given that the most abundant species have a higher probability of interacting with other species (Vázquez et al. 2007), it should be expected that, in the study area, the plant-frugivore interaction network would be characterized by small, abundant species occupying central positions within the network. In other words, certain network positions that were occupied by species which disappeared locally are now occupied by species with different ecological and morphological characteristics, which prevents a structural breakdown of the network but does not necessarily maintain the functionality of the ecosystem. As such, there may be plant species that lost their original dispersers and their new dispersers are not as effective due to different ecological and morphological characteristics. From a functional standpoint, large frugivorous birds are important dispersers for species with large fruits playing a key role in demographic aspects (Vidal et al. 2013, Muñoz et al. 2016, Donoso et al. 2017b). From a restoration perspective large birds can distribute seeds between distant patches facilitating the functional connectivity of fragmented landscapes (Kays et al. 2011, Mueller et al. 2014). Large seeded species such as Spondias mombin, Pouteria glomerata and Clavija mezii were observed in fruit, but we did not record any birds eating them.

In conclusion, in a disturbed ecosystem, although the interaction networks maintain an interconnected structure amongst species, the importance of a particular species within such structure depends on its ecological and morphological attributes as well as on the availability of resources in the area. The frequency and distribution of these traits in the community may be determined by the disturbance of a particular area. For example, in this study we observed that, contrary to our expectation, large frugivores have little structural importance, which may be due to a negative selection toward large animals in disturbed ecosystems that led to local extinction or decreased populations sizes (Redford 1992, Renjifo 1999, Markl et al. 2012, Emer et al. 2018). As a result, the interaction network is mainly structured by species that are small and abundant. Nonetheless, it should be noted that structural importance does not necessarily imply ecological functionality (Muñoz et al. 2016). It is important to recognize that our results could be more conclusive if we had a control case in an undisturbed ecosystem. The forests of the Uraba plains have been heavily transformed (Etter et al. 2006, SánchezCuervo and Aide 2013) but future studies in additional fragments would greatly complement the results obtained here. Therefore, we suggest that future studies combine structural evaluation of the network with the functional role of species in specific ecological processes, such as seed dispersal. It will be specifically important to study the response capacity and compensatory effects among plant species with large fruit 
when their dispersers disappear. Finally, this study shows that interaction networks and the evaluation of their structural patterns are a useful tool for identifying species with relevant roles. This information is important when evaluating the effects of species that have disappeared as a result of anthropic actions.

Acknowledgements: SMA was supported by the Alejandro Ángel Escobar Foundation through the Colombia Biodiversa Grant. JFAQ was supported by a National Doctoral scholarship from COLCIENCIAS $(647,2015-$ II). We also would like to thank IDEA WILD for the support with equipment for field sampling. We are grateful with the herbarium at the Universidad de Antioquia (HUA) for kindly providing the data for the plant plots and with the Sede de Estudios Ecológicos y Agroambientales Tulenapa administration for logistical support. We thank the students and colleagues who helped us during field sampling and to M. C. Vargas, A. Idárraga and S. Murillo Serna for the help with botanical identifications. We appreciate the contributions from $\mathrm{C}$. López Gallego, J. Gastón Zamora, the Vertebrate Ecology and Evolution Research Group at the Universidad de Antioquia, two anonymous reviewers and the editor that helped us improve this manuscript.

\section{References}

APG IV. 2016. An update of the Angiosperm Phylogeny Group classification for the orders and families of flowering plants : APG IV. Bot. J. Linn. Soc. 181:1-20.

Audubon, and Cornell Lab of Ornithology. 2018. eBird. https://ebird. org/explore.

Barthélemy, M. 2004. Betweenness centrality in large complex networks. Eur. Phys. J. B 38:163-168.

Bascompte, J. and P. Jordano. 2007. Plant-animal mutualistic networks: the architecture of biodiversity. Annu. Rev. Ecol. Evol. Syst. 38:567-593.

Bates, D., M. Mächler, B. Bolker and S. Walker. 2015. Fitting linear mixed-effects models using lme4 67. J. Stat. Softw. 67(1):1-48.

Bibby, C., M. Jones and S. Marsden. 1998. Expedition Field Techniques Bird Surveys. Expedition advisory centre of the Royal Geographical Society, London.

Buckton, S.E.B. 2001. Threatened Birds of the World. Birdlife International (2000). Barcelona and Cambridge, UK: Lynx Edicions and BirdLife International. Page Bird Conservation International. Cambridge University Press. ??

Ceballos, G., and P.R. Ehrlich. 2002. Mammal population losses and the extiction crisis. Science 296:904-907.

Chacoff, N.P., D.P. Vázquez, S.B. Lomáscolo, E.L. Stevani, J. Dorado and B. Padrón. 2012. Evaluating sampling completeness in a desert plant-pollinator network. J. Anim. Ecol. 81:190-200.

Chao, A., R.K. Colwell, C.W. Lin and N.J. Gotelli. 2009. Sufficient sampling for asymptotic minimum species richness estimators. Ecology 90:1125-1133.

Christiansen, M.B. and E. Pitter. 1997. Species loss in a forest bird community near Lagoa Santa in southeastern Brazil. Biol. Conserv. 80:23-32.

Colorado, G. de J. 2013. Landbird monitoring program at Tulenapa research station, Carepa Municipality, Northwestern Colombia. The Nature Conservancy.
Colwell, R.K. 2013. EstimateS: Biodiversity Estimation of species richness and shared species from samples. Version 9.1.0. published at: purl.oclc.org/estimates.

Dehling, D.M., P. Jordano, H.M. Schaefer, K. Böhning-Gaese and M. Schleuning. 2016. Morphology predicts species' functional roles and their degree of specialization in plant-frugivore interactions. P. R. Soc. B: Biological Sciences 283:20152444.

Dehling, D.M., T. Töpfer, H.M. Schaefer, P. Jordano, K. BöhningGaese and M. Schleuning. 2014. Functional relationships beyond species richness patterns: Trait matching in plant-bird mutualisms across scales. Global Ecol. Biogeogr. 23:1085-1093.

Dirección de Regionalización Universidad de Antioquia. 2011. Propuesta académica para la creación del centro de estudios biológicos Tulenapa, Carepa, Antioquia.

Dirzo, R., H.S. Young, M. Galetti, G. Ceballos, N.J.B. Isaac and B. Collen. 2014. Defaunation in the Anthropocene. Science 345:401-406.

Donatti, C.I., P.R. Guimarães, M. Galetti, M.A. Pizo, F.M.D. Marquitti and R. Dirzo. 2011. Analysis of a hyper-diverse seed dispersal network: Modularity and underlying mechanisms. Ecol. Lett. 14:773-781.

Donoso, I., D. García, D. Martínez, J. M. Tylianakis and D.B. Stouffer. 2017a. Complementary effects of species abundances and ecological neighborhood on the occurrence of fruit-frugivore interactions. Front. Ecol. Evol. 5:133.

Donoso, I., M. Schleuning, D. García and J. Fründ. 2017b. Defaunation effects on plant recruitment depend on size matching and size trade-offs in seed-dispersal networks. P. R. Soc. B. 284:20162664

Dormann, C. F., J. Fruend, B. Gruber, M. Devoto, J. Iriondo, R. Strauss and D. Vazquez. 2017. Package "barpartite." online PDF.

Emer, C., M. Galetti, M. A. Pizo, P. R. J. Guimarães, S. Moraes, A. Piratelli and P. Jordano. 2018. Seed-dispersal interactions in fragmented landscapes - a metanetwork approach. Ecol. Lett. 21: 484-493.

Escobar-Cardona, O. and H. Alvarez-Lopez. 1966. Estudio ecologico prelimirar del parque nacional del río León-Antioquia. Universidad Nacional de Colombia Sede Medellín.

Escribano-Avila, G., C. Lara-romero, R. Heleno, and A. Traveset. 2018. Tropical seed dispersal networks: emerging patterns, biases, and keystone species traits. In: Rico-Gray, V. and W. Dáttilo (eds.), Ecological Networks in the Tropics. Springer, Cham. pp. 93-110.

Estrada, E. 2007. Characterization of topological keystone species. Local, global and "meso-scale" centralities in food webs. Ecol Complex. 4:48-57.

Etter, A., C. McAlpine., K. Wilson., S. Phinn and H. Possingham. 2006. Regional patterns of agricultural land use and deforestation in Colombia. Agr. Ecosyst. Environ. 114: 369-386.

Feeley K.J. and J.W. Terborgh. 2008. Direct vs. indirect effects of habitat reduction on the loss of avian species from tropical forest fragments. Anim. Conserv. 11: 353-360.

Fox, J. 2015. Applied Regression Analysis and Generalized Linear Models. SAGE Publications, USA.

Gard, T.C. 1984. Persistence in food webs. In: S. Levin and T. Hallam (eds.), Mathematical Ecology. Springer, Berlin. pp. 208-219.

Henle, K., K.F. Davies, M. Kleyer, C. Margules and J. Settele. 2004. Predictors of species sensitivity to fragmentation. Biodivers. Conserv. 13:207-251.

Howe, H.F. and J. Smallwood. 1982. Ecology of seed dispersal Annu. Rev. Ecol. Syst. 13:201-228. 
Jordán, F., W. Liu, A. J. Davis, J. Memmott, F. Jordan, W. Liu and A. J. Davis. 2006. Topological keystone species : measures of positional importance in food webs. Oikos 112:535-546.

Jordano, P. 2000. Fruits and frugivory. In: M. Fenner (ed.), Seeds: The Ecology of Regeneration in Plant Communities. 2nd edition. CABI Publ., Wallingford. pp. 125-165.

Jordano, P. 2016. Sampling networks of ecological interactions. Funct. Ecol. 30:1883-1893.

Jordano, P., D. Vazquez and J. Bascompte. 2009. Redes complejas de interacciones mutualistas planta-animal. In: Medel, R, Aizen, M. A. and R. Zamora (eds.), Ecología y evolucion de interacciones planta-animal. Editorial Universitaria, Santiago de Chile. pp. 17-41.

Karr, J.R. 1976. Seasonality, resource availability , and community diversity in tropical bird communities. Am. Nat. 110:973-994.

Kattan, G. H., H. Alvarez-Lopez and M. Giraldo. 1994. Forest fragmentation and bird extinctions. San Antonio eight years later. Conserv. Biol. 8:138-146.

Kays, R., P. A. Jansen, E. M. H. Knecht, R. Vohwinkel and M. Wikelski. 2011. The effect of feeding time on dispersal of Virola seeds by toucans determined from GPS tracking and accelerometers. Acta Oecol. 37:625-631.

Markl, J.S., M. Schleuning, P.M. Forget, P. Jordano, J.E. Lambert, A. Traveset, S. J. Wright and K. Böhning-Gaese. 2012. Metaanalysis of the effects of human disturbance on seed dispersal by animals. Conserv. Biol. 26:1072-1081.

Martín González, A.M., B. Dalsgaard and J.M. Olesen. 2010. Centrality measures and the importance of generalist species in pollination networks. Ecol Complex. 7:36-43.

Mello, M.A.R., F.A. Rodrigues, L. da F. Costa, W.D. Kissling, Ç. H. Şekercioğlu, F.M.D. Marquitti and E.K.V. Kalko. 2014. Keystone species in seed dispersal networks are mainly determined by dietary specialization. Oikos 124:1031-1039.

Mueller, T., J. Lenz, T. Caprano, W. Fiedler and K. Böhning-Gaese. 2014. Large frugivorous birds facilitate functional connectivity of fragmented landscapes. J. Appl. Ecol. 51:684-692.

Muñoz, M.C., H.M. Schaefer, K. Böhning-Gaese and M. Schleuning. 2016. Importance of animal and plant traits for fruit removal and seedling recruitment in a tropical forest. Oikos 126:823-832.

Newman, M.E.J. 2003. The structure and function of complex networks. Soc. Ins. Appl. Math. 45(2):167-256.

Olesen, J.M., J. Bascompte, Y.L. Dupont, H. Elberling, C. Rasmussen and P. Jordano. 2011. Missing and forbidden links in mutualistic networks. P. R. Soc. B-Biol. Sci. 278:725-732.

Palacio, R.D., C. Valderrama-Ardila, and G.H. Kattan. 2016. Generalist species have a central role in a highly diverse plant frugivore network. Biotropica 43:349-355.

Peres, C. and E. Palacios. 2007. Basin wide effects of game harvest on vertebrate population densities in amazonian forests: implications for animal mediated seed dispersal. Biotropica 39:304-315.

Pimm, S., P. Raven, A. Peterson, Ç.H. Şekercioğlu and P.R. Ehrlich. 2006. Human impacts on the rates of recent, present, and future bird extinctions. P. Natl. Acad. Sci. USA 103:10941-10946.

R Develoment Core Team. 2017. R: The R Project for Statistical Computing.

Redford, K.H. 1992. The Empty Forest. BioScience 42:412-422.

Remsen, J.V.J., C.D. Cadena, S. Claramunt, A. Jaramillo, J.F. Pachecho, J. Pérez-Emán, M.B. Robbins, F.G. Stiles, D.F. Stotz and K.J. Zimmer. 2018. South American Classification Committee. http:// www.museum.lsu.edu/ Remsen/SACCBaseline.htm.
Renjifo, L.M. 1999. Composition changes in a subandean avifauna after long-term forest fragmentation. Conserv. Biol. 13:11241139.

Saavedra, S., D.B. Stouffer, B. Uzzi and J. Bascompte. 2011. Strong contributors to network persistence are the most vulnerable to extinction. Nature 478:233-235.

Sanchez-Cuervo, A.M., and T.M. Aide. 2013. Identifying hotspots of deforestation and reforestation in Colombia (2001-2010): implications for protected areas. Ecosphere 4(11): 1-21.

Sarmento, R., C.P. Alves-Costa, A. Ayub, and M.A.R. Mello. 2014. Partitioning of seed dispersal services between birds and bats in a fragment of the Brazilian Atlantic Forest. Zoologia-Curitiba 31:245-255.

Sazima, C., P.R. Guimarães, S.F. dos Reis, and I. Sazima. 2010. What makes a species central in a cleaning mutualism network? Oikos 119:1319-1325.

Sebastián-González, E. 2017. Drivers of species' role in avian seeddispersal mutualistic networks. J. Anim. Ecol. 86:878-887.

Tylianakis, J.M., E. Laliberté, A. Nielsen and J. Bascompte. 2010. Conservation of species interaction networks. Biol. Conserv. 143:2270-2279.

Vázquez, D.P., C.J. Melián, N.M. Williams, N. Blüthgen, B.R. Krasnov and R. Poulin. 2007. Species abundance and asymmetric interaction strength in ecological networks. Oikos 116:1120-1127.

Vidal, M.M., E. Hasui, M., Pizo, J.Y. Tamashiro, W.R. Silva and P. R. Guimarães. 2014. Frugivores at higher risk of extinction are the key elements of a mutualistic network. Ecology 95:3440-3447.

Vidal, M.M., M.M. Pires and P.R. Guimarães, Jr. 2013. Large vertebrates as the missing components of seed-dispersal networks. Biol. Conserv. 163:42-48.

Willis, E.O. 1979. The Composition of avian communities in remanescent woodlots in Southern Brazil. Pap. Avulsos de Zool. (São Paulo) 33(1):1-26.

Wilman, H., J. Belmaker, J. Simpson, C. de la Rosa, M.M. Rivadeneira, and W. Jetz. 2014. EltonTraits 1.0: Species-level foraging attributes of the world's birds and mammals. Ecology 95:2027.

Received August 6, 2018 Revised October 24, 2018 Accepted December 12, 2018

\section{Supplementary material}

Table A1. Traits of bird species.

Table A2. Quantitative interaction matrix.

Table A3. ID Nodes.

The appendix may be downloaded from www.akademiai. com.

Open Access statement. This is an open-access article distributed under the terms of the Creative Commons Attribution-NonCommercial 4.0 International License (https://creativecommons.org/licenses/by-nc/4.0/), which permits unrestricted use, distribution, and reproduction in any medium for non-commercial purposes, provided the original author and source are credited, a link to the CC License is provided, and changes - if any - are indicated. 